\title{
The role of co-administration of damage control surgery and vacuum-assisted closure in the treatment of perineal wounds
}

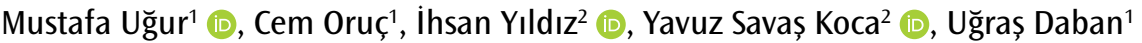

Perineal wounds caused by high-kinetic-energy shotgun blasts have a high mortality risk because they are often accompanied by injuries of the anus, rectum, genitourinary system, and extremities. Mortality often results from hemorrhage in the early stage and from multiple organ failure caused by sepsis in the late stage. The primary step in the treatment of patients presenting with perineal wound and hemodynamic instability caused by severe hemorrhage is to control hemorrhage and contamination using damage control surgery. After achieving hemodynamic stability, vacuum-assisted closure can be used to reduce the risks of infection and sepsis. In this report, we present a case who had a perineal wound caused by a mine blast and was successfully treated by damage control surgery and vacuum-assisted closure.

Keywords: Perineal wound, mine blast, vacuum-assisted closure
\end{abstract}

ORCID IDs of the authors: M.U. 0000-0002-5922-2367; i.Y. 0000-0002-6804-7492: Y.S.K. 0000-0001-6543-3622

Cite this paper as: Uğur $M$, Oruç C, Yıldız I, Koca YS, Daban U.The role of co-administration of damage control surgery and vacuum-assisted closure in the treatment of perineal wounds. Turk J Surg 201834 (3):229-230.

'Department of General Surgery, Mustafa Kemal University School of Medicine, Hatay, Turkey

2Department of General Surgery, Süleyman Demirel University School of Medicine, Isparta, Turkey

Corresponding Author Mustafa Uğur e-mail:drmustafaugur@gmail.com

Received: 27.06.2015 Accepted: 04.10.2015 Available Online Date: 03.01.2018

ocopyright 2018 by Turkish Surgical Association Available online at www.turkjsurg.com

\section{INTRODUCTION}

Experience in the management of traumatic perineal wounds has been largely gained through the management of battlefield traumas. Perineal wounds caused by high-kinetic-energy shotgun blasts have a high mortality risk because they are often accompanied by injuries of the anus, rectum, genitourinary system, and extremities. Mortality often results from hemorrhage in the early stage and from multiple organ failure caused by sepsis in the late stage (1-3). Recent attempts have been made to decrease mortality rates by effectively using damage control surgery (DCS) techniques and by inducing protection against infection (4).

In this study, we report a case who had a perineal wound caused by a mine blast and was successfully treated by DCS and vacuum-assisted closure (VAC).

\section{CASE PRESENTATION}

The 24-year-old male patient was transferred to our hospital from a neighboring country where he had been wounded due to a mine blast during a civil war. A statement from paramedics revealed that the blast occurred approximately five hours before transportation, and the patient was transferred to the border following ginitial surgery at a location close to the combat arena. Physical examination revealed a body temperature of $35.6^{\circ} \mathrm{C}$ and a systolic blood pressure of $75 \mathrm{mmHg}$. The patient had a midline abdominal surgical incision. The perineal skin had been closed using a Y-shaped suture pattern. The patient was transferred to the intensive care unit (ICU). Heating pads and radiant heaters were used to prevent further heat loss. Fluid and electrolyte resuscitation was started. All fluids were warmed to body temperature before transfusion. The patient's arterial blood gas $\mathrm{pH}$ was 7.15, and his whole blood count revealed a hemoglobin level of $6.9 \mathrm{mg} / \mathrm{dL}$ and an international normalized ratio (INR) of 2.1. On the basis of these values, resuscitation was continued with the administration of 3 units of erythrocyte suspension that were previously warmed to body temperature and 2 units of fresh frozen plasma. At $24 \mathrm{~h}$ after admission to the ICU, the patient's parameters were as follows: systolic blood pressure; $95 \mathrm{mmHg}$, body temperature: $36.9^{\circ} \mathrm{C}$, arterial $\mathrm{pH}: 7.31$, hemoglobin: $9.0 \mathrm{mg} / \mathrm{dL}$, and INR: 1.5.Abdominal and pelvic computed tomography revealed fragmented fractures and multiple foreign bodies suggestive of compressin the perineal region. The orthopedics department was consulted regarding the fragmented pelvic fractures. On this basis of the consultation, the patient was immobilized for one month. The surgical procedure was started by removing the sutures and compresses in the perineal region. Exploration revealed a $30 \times 25 \mathrm{~cm}$ necrotic wound around the anus with no hemorrhage. No anorectal wound was observed by perioperative anoscopy. After debridement, the external sphincter was completely intact. The wound site was irrigated with physiologic serum and dressing was performed using the VAC method. The abdomen was entered through the previous incision site. Surgical exploration revealed that the sigmoid colon had been split at the distal end and had been primarily closed at both the proximal and distal ends. The sutures at the proximal end of the sigmoid colon were opened and sigmoid end colostomy was performed. The patient was extubated on postoperative day 1 . Dressing was performed by applying negative pressure using the VAC method. Following the formation of granulation tissue, the perineal defect was closed by a skin graft obtained from the anterior surface of the left femur. The patient was discharged on postoperative day 15. Written informed consent was obtained from patient who participated in this case. 


\section{DISCUSSION}

Uncontrollable hemorrhage and sepsis are the most common challenges in the management of traumatic pelvic wounds. The pelvis is a complex anatomical region that is neighbored by several organs and systems. Therefore, no standard treatment has been established for the management of pelvic wounds. Treatment is commonly based on a multidisciplinary approach including the disciplines of general surgery, orthopedics, and anesthesiology. However, because the combat arena is generally characterized by irregular warfare, riots, and uprisings, the healthcare facilities present in combat arenas are usually disrupted by poverty and battle. Moreover, the transportation of casualties to health centers is hindered by destroyed roads, difficult terrain conditions, and long distances. In addition, the extensive number of casualties often outweighs the capacity of healthcare facilities available in the combat arena. Due to these factors, combat casualties generally present to health centers with deep hemorrhagic shock $(4,5)$.

Damage control surgery remains the mainstay treatment for casualties presenting with acidosis, hypothermia, coagulopathy, and hemodynamic instability. The principle aims of DCS are to achieve primary repair of major arterial injuries, to perform arterial ligation, or to prevent hemorrhage by packing with compression bags. In addition, in the treatment of hollow organ wounds, a subsequent primary repair should be performed to prevent contamination. In these patients, the duration of surgery should not exceed one hour. Procedures such as ileostomy and colostomy should be avoided because they are highly time consuming. The patient should be directly transferred to the ICU, and the initial aim should be to correct acidosis and hypothermia. After hemodynamic stability is achieved, definitive surgery should be performed. The decision to perform DCS should be made depending on the initial evaluation of the patient or the findings obtained within the first 15 minutes of surgery $(6,7)$.

Our patient had a perineal wound caused by a mine blast that occurred during a civil war in a neighboring country. The patient had undergone surgery at a location close to the combat arena before transportation. In such cases, amajor problem is that no medical document ation regarding the condition of the patient is transported with the patient or that the document is lost during transportation.The medical condition of our patient indicated that the hemorrhage may have been controlled by placing compresses on the perineum. Moreover, it is likely that the surgeons decided to perform DCS because no colostomy had been performed during laparotomy and both ends of the sigmoid colon had been closed. Ultimately, the surgeons probably decided to transfer the patient to our hospital due to the absence of appropriate facilities for postoperative resuscitation. Upon initial examination at our hospital, the patient presented with acidosis, hypothermia, and hemodynamic instability. The definitive surgery was performed after achieving resuscitation.

High-kinetic-energy shotgun wounds lead to large amounts of devitalized and contaminated tissues that have a high risk of infection. To reduce this risk, aggressive debridement and daily dressing changes hould be performed. Perineal wounds have a particularly high risk of infection because fecal contamination is inevitable. In these wounds, daily dressing changes are another challenge for treatment. VAC can be an ideal option for overcoming these difficulties. This method allows continuous drainage of contaminated and complicated wounds. It also reduces the level of exudate, debris, and bacteria. Moreover, it facilitates the removal of large amounts of fluid in deep wounds.
After initial debridement and irrigation, VAC is performed to apply negative pressure, and the dressing is changed every 24 to $48 \mathrm{~h}$. Following revitalization of the tissues and the formation of granulation tissue, the wound is closed using either primary closure, flap advancement, or skin graft $(8,9)$.

Our patient had a large necrotic wound in the perineal region. The wound was closed after creating negative pressure by VAC. The dressing was changed every $48 \mathrm{~h}$. The tissues were revitalized and granulation tissue was formed on postoperative day 10 . The defect was closed by a whole-layer skin graft obtained from the anterior surface of the left femur. No complications were observed in the follow-up period. The patient was discharged on day 15 and was advised to visit our clinic for colostomy closure 8 weeks later. However, the patient has not returned for colostomy closure although more than 8 weeks have passed since discharge.

\section{CONCLUSION}

Damage control surgery and the proper administration of its principles can be lifesaving in patients with high-kinetic-energy shotgun wounds who present with hemodynamic instability. In addition, VAC may facilitate treatment by preventing the risks of soft tissue necrosis and serious infection, particularly in wounds that are located in difficult regions of the body.

Informed Consent: Written informed consent was obtained from patient who participated in this study.

Peer-review: Externally peer-reviewed.

Author Contributions: Concept - M.U., U.D., Y.S.K.; Design - M.U., I.Y., C.O.; Supervision - M.U., U.D., Y.S.K.; Resource - U.D., M.U., C.O.; Materials - C.O., U.D.; Data Collection and/or Processing -U.D., M.U., C.O.; Analysis and/or Interpretation - M.U., U.D., Y.S.K.; LiteratureSearch - M.U., I.Y., C.O.; Writing Manuscript - M.U., Y.S.K., I.Y.; Critical Reviews - I.Y., Y.S.K., M.U.

Conflict of Interest: The authors have no conflicts of interest to declare.

Financial Disclosure: The authors declared that this study has received no financial support.

\section{REFERENCES}

1. MacFarlane C, Vaizey $C J$, Benn CA. Battle injuries of the rectum: options for the field surgeon. J R Army Med Corps 2002; 148: 2731. [CrossRef]

2. Özkan S, Yağmur Ö, Özkan FC, Alabaz Ö, Sönmez H. Anal kanalveperineyaralanmaları. Ulus Travma Acil Cerrahi Derg 1998; 4: 28-32.

3. Schoenfeld AJ. The combat experience of military surgical assets in Iraq and Afghanistan: a historical review. Am J Surg 2012; 204: 377-383. [CrossRef]

4. Arthurs Z, Kjorstad R, Mullenix P, Rush RM Jr, Sebesta J, Beekley A. The use of damage-control principles for penetrating pelvic battlefield trauma. Am J Surg 2006; 191: 604-609. [CrossRef]

5. Giannou C, Baldan M. Neglected or Mismanaged Wounds. In: Giannou C, Baldan M, eds. War surgery: working with limited resources in armed conflict and other situations of violence. Vol. 1. Geneva: International Committee of the Red Cross, 2010; 243-251.

6. Stagnitti F. Uncontrolled bleeding in patients with major abdominal trauma. Ann Ital Chir 2013; 84: 365.

7. Cirocchi R, Montedori A, Farinella E, Bonacini I, Tagliabue L, Abraha I. Damage control surgery for abdominal trauma. Cochrane Database Syst Rev 2013; 28: CD007438. [CrossRef]

8. Leininger $B E$, Rasmussen $T E$, Smith $D L$, Jenkins $D H$, Coppola $C$. Experience with wound $V A C$ and delayed primary closure of contaminated soft tissue injuries in Iraq. J Trauma 2006; 61: 12071211. [CrossRef]

9. Gümüş N. Vacuum-assisted closure of perineal war wound related to rectum. Eplasty 2009; 13: e55. 